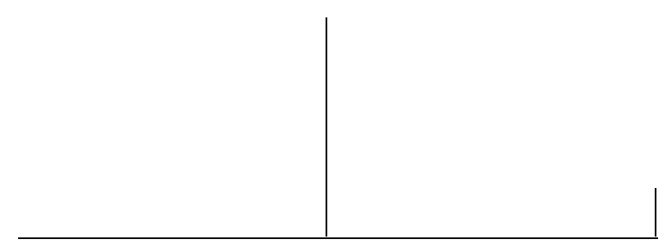

Rev. Latinoam. Psicopat. Fund., São Paulo, v. 14, n. 4, p. 627-641, dezembro 2011

\title{
Eugenizar a alma: a constituição da euphrenia no projeto de higiene mental voltado à infância da Liga Brasileira de Hygiene Mental*
}

Cristiane Oliveira

O presente artigo analisa a constituição da "euphrenia" como um novo domínio para a psiquiatria brasileira na sua abordagem eugênica e higiênica da infância. A análise de saberes médicos e psicológicos acerca do psiquismo infantil no Brasil das décadas de 1920 e 1930 descortina a intensa circulação afetiva intrafamiliar como ponto de ancoragem para um projeto de normalização social, ainda centrado na eugenia, mas já atravessado por uma psicologia da adaptação.

Palavras-chave: Euphrenia, saberes médicos e psicológicos, família, Liga Brasileira de Hygiene Mental

* Este artigo foi extraído de minha tese de doutorado intitulada A regulação política da sexualidade no âmbito da família por saberes e instituições médicas brasileiras (1838-1940), defendida no Programa de Pós-graduação em Saúde Coletiva do Instituto de Medicina Social da Universidade do Estado do Rio de Janeiro - IMS/UERJ e vinculado à linha de pesquisa Subjetividade e História da área de concentração Ciências Humanas e Saúde.

Nas citações do período abrangido pela pesquisa, foram mantidas a ortografia, acentuação e pontuação vigentes na época. 


\section{Introdução}

O cuidado médico novecentista com a criança, centrado nas preocupações com a alimentação, as vestimentas e a higiene, ganhou notável expansão na primeira metade do século XX, quando a criança já havia se convertido no principal alvo de investimento da família. O imperativo não era apenas o de constituir um corpo saudável, mas revirar todos os cantos da alma infantil, a fim de detectar precocemente as ameaças não apenas à sua vida, mas à sua evolução mental.

Tratava-se, então, de superar o antigo modelo de compreensão da vida na tenra infância, baseado na ideia de que o infante se relacionava com o meio exclusivamente a partir do sistema digestivo e respiratório, e substituí-lo por um novo modelo, marcado por uma compreensão neuropsicológica na qual uma intricada rede de conceitos e processos poderia explicar a suscetibilidade psíquica da criança aos estímulos externos.

No arcabouço do projeto vintecentista de higiene mental, que passará a se ocupar de modo muito significativo da infância, os adultos eram vistos como seres já deteriorados por taras e vícios educativos, de modo que não se conseguiria com eles demonstrar a eficácia profilática necessária ao crescimento político da psiquiatria, num momento em que uma importante descontinuidade estava se consolidando, tanto no que tocava ao âmbito do saber quanto ao âmbito institucional (Portocarrero, 2002). Por essas razões, a profilaxia mental deveria atingir sobretudo as crianças (Reis, 2000), pois elas ofereciam condições favoráveis a uma intervenção exitosa da psiquiatria. À família, ao Estado e à escola estava endereçado um conjunto de prescrições acerca da evolução normal do psiquismo. 
O presente trabalho analisa a constituição da "euphrenia" como um novo domínio para a psiquiatria brasileira na sua abordagem eugênica e higiênica da vida mental das crianças. Para tanto, descreve as linhas principais do projeto de higiene mental protagonizado institucionalmente pela Liga Brasileira de Hygiene Mental (LBHM); discute o lugar das preocupações do psiquismo infantil no escopo deste projeto; analisa a emergência da eufrenia, enquanto um novo domínio do saber psiquiátrico; e, finalmente, problematiza a família como instância privilegiada de realização deste projeto.

De inspiração foucaultiana (Foucault, 2000; 2001; 2005a; 2005b), o presente trabalho se inscreve na história dos saberes e toma como pressuposto metodológico fundamental a ideia de que os conceitos de um campo científico devem ser analisados tomando-se por referência o solo político e social que o fundamenta e não apenas a partir de uma perspectiva estritamente epistemológica. Para tanto, foram considerados como documentos elegíveis os artigos publicados, entre as décadas de 1920 e 1930, nos Archivos Brasileiros de Hygiene Mental, órgão oficial de divulgação dos trabalhos da Liga Brasileira de Hygiene Mental.

\section{A psiquiatria como ciência da anomalia: o trabalho da LBHM}

O interesse pelo psiquismo infantil se inseriu no âmbito de uma nova forma de intervenção social da psiquiatria, que se nomeou, ainda na década de 1920, como higiene mental. Antes que a LBHM pudesse dar voz institucional a esse projeto, a profilaxia mental no Brasil já começa a se esboçar desde o começo do século. Juliano Moreira, em 1906, vislumbrou a tendência de conversão da psiquiatria num saber destinado à profilaxia mental. Mas a institucionalização desse projeto ficou a cargo de Gustavo Riedel, então diretor da Colônia de Psychopatas do Engenho de Dentro, onde, em 1919, fundou o primeiro Instituto de Prophylaxia Mental da América do Sul e, em 1923, a LBHM (Caldas, 1930).

No seu momento inaugural, a LBHM assumiu como funções o combate das causas das doenças mentais e nervosas, a assistência aos doentes mentais e a atenção aos predispostos a psicopatias, com finalidade profilática. Um outro vetor de sua ação foi o combate ao alcoolismo, entendido à época como flagelo nacional, debilitante do sistema nervoso e predisponente à disseminação de doenças, como as nervosas e mentais, além de doenças venéreas e crimes. A luta antialcoólica, aliás, contava com o apoio do Estado, que reconhecia sua utilidade pública, subvencionando-a pecuniariamente, ainda que de maneira intermitente. A LBHM contava igualmente com o apoio de juristas, educadores, jornalistas, além, claro, dos médicos. As ações comportaram ainda a instalação de um laboratório de 


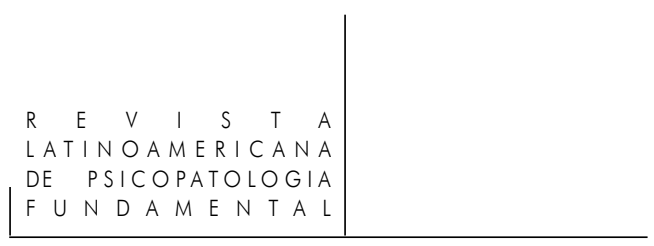

psicologia aplicada, voltado para seleção e orientação profissionais, inaugurando no Brasil a psicometria, destinada à seleção dos "mais aptos", mais adaptáveis ao mundo da produção (Caldas, 1930).

Já nos primeiros anos de trabalho, funcionou um "consultório de psicoanálise", coordenado por Porto-Carrero, entre 1926 e 1927, vinculado às ações ambulatoriais da Liga. Comentando a experiência na ocasião, o autor tenta demonstrar a pertinência da psicanálise, enquanto método terapêutico, ao projeto de higiene mental da LBHM. Argumentava que o saber da psicanálise, que oferecia acesso aos "complexos recalcados" - precisamente o Complexo de Édipo e o de Castração - permitiria que se pudesse operar com um conjunto bastante ampliado de fenômenos psicopatológicos que estivessem à margem do que se considerava estritamente como loucura.

O trabalho psicanalítico na LBHM não se restringiria, portanto, aos atendimentos ambulatoriais. Seu programa envolveria uma intervenção na formação das professoras primárias, para que estas pudessem realizar educação sexual e exercer vigilância dos comportamentos das crianças, de modo a identificar os "pequenos contraventores", obstruindo sua conversão, dada como certa, em adultos criminosos; emprego de táticas de correção junto ao Juizado de Menores para tratar os contraventores e criminosos; educação sexual para a sociedade em geral, com o auxílio dos meios de comunicação de massa (conferências radiofônicas e artigos de jornal). Envolveria ainda tratamento aos toxicômanos, pervertidos sexuais, suicidas e neuróticos em geral (Porto-Carrero, 1929).

O que era novo não era a aproximação da psiquiatria com a higiene, já que esse gesto esteve presente desde os primeiros instantes de inserção do saber psiquiátrico no cenário brasileiro, na primeira metade do século XIX. Como Machado et al. (1978) já fizeram notar, havia uma solidariedade entre a medicina social e a psiquiatria nascente, manifesta pelo interesse em comum de normalizar o espaço público. Com efeito, o projeto da medicina social não poderia ser levado a cabo sem a ajuda da psiquiatria, pois ela dispunha do arsenal técnico e teórico - asilo e a terapêutica moral - que pudesse justificar que a intromissão higienista chegasse a determinar quem poderia circular livremente no espaço público e quem deveria estar impedido de fazê-lo, por representar perigo ao social. No entanto, a psiquiatria nesse momento não se constituía como "preventiva", ou seja, ela não tinha a pretensão de realizar profilaxia das doenças mentais, como será o caso a partir da década de 1920, com a institucionalização do projeto de higiene mental.

A LBHM apoiava, politicamente, o discurso de fortalecimento eugênico da população, mas deixava entrever que o projeto da higiene mental estava também voltado para garantir que os indivíduos pudessem ser tratados pela psiquiatria, a 
despeito da predisposição à degeneração. A psiquiatria começa a se voltar para os que supostamente seriam normais ou para aqueles cujas manifestações das "taras hereditárias" pudessem ser mitigadas pelo adestramento mental proposto em seu programa. A oferta psiquiátrica passará a conjugar o controle estrito da herança, pela defesa da eugenia, com a educação dos "instintos" na direção da adaptação ao convívio social. Coerente com o projeto de adaptação que se insinuava no interior do discurso da higiene mental, justificava-se o interesse na prevenção da formação não apenas do "degenerado", mas também do "desajustado" (Porto-Carrero, 1929; Caldas, 1930).

Há uma ressignificação do papel da herança na etiologia dos distúrbios psíquicos, a partir da assimilação da genética mendeliana pelos psiquiatras da Liga. Numa ata da assembleia geral ordinária da LBHM, em 1928, consta o relato de uma intervenção de Juliano Moreira acerca dos fatores hereditários em psiquiatria, na qual ele sinalizava que a compreensão do tema da "herança" não deveria, no que dizia respeito à esfera mental, ser vinculado à inexorabilidade da degenerescência. Subsidiado pelas ideias mendelianas acerca da hereditariedade, Moreira toma os conceitos de recessividade e dominância, para afirmar que apenas a herança dominante é diretamente transmitida; a herança recessiva não o seria, o que ele demonstra a partir de algumas análises genealógicas de casos de doença mental.

Essa nova forma de tratar a hereditariedade punha a "doença mental" num jogo probabilístico de ocorrência tal que se tornava difícil sustentar o modelo determinista e generalizado de outrora. Além disso, o peso da degenerescência no nexo causal deveria diminuir na medida em que a própria natureza se encarregaria de criar barreiras, afirmação que estava subsidiada pela descoberta dos mecanismos de transmissão da recessividade, que colocaria impedimentos "naturais" à reprodução dos "doentes mentais", além do equilíbrio da qualidade populacional fornecido pela reprodução dos cônjuges sadios, favoráveis que seriam à regeneração. Além disso, o controle da "doença mental" apenas pela hereditariedade esbarrava no problema da transmissão silenciosa dos padrões recessivos, já que alguém aparentemente saudável, e portanto não passível de qualquer controle eugênico, transmitiria seu patrimônio genético predisponente à patologia aos descendentes.

É nessa perspectiva que Fontenelle (1925) distingue, no projeto mais amplo da higiene mental, um duplo objetivo: prevenir as causas da degeneração psíquica (profilaxia mental) e promover a adaptação do indivíduo ao meio físico e social (que equivaleria à higiene mental propriamente dita). Essa bifurcação explicita bem a filiação política, de um lado, à eugenia e, de outro, a uma psicologia da adaptação. Os termos "fracassos de ajustamento" e "adaptação" já aparecem nesse texto de 1925. Três conceitos o fundamentam: “... a estrutura psíquica do 


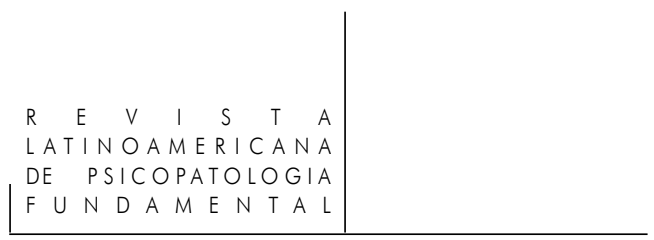

indivíduo", dependente da hereditariedade, a noção de meio (físico e social), ao qual o indivíduo deveria se adaptar, e a formação dos "hábitos", práticas corporais e mentais cuja regularidade permitiria ao indivíduo adaptar-se às exigências do meio.

É uma psiquiatria que se entranha nas mínimas idiossincrasias para capturar as manifestações de anormalidade. Tratava-se de não mais restringir a atuação psiquiátrica à assistência à alienação, cujos equipamentos "terapêuticos" eram o tratamento moral e o isolamento em hospício, mas intervir de modo profilático no espaço social, tão saturado de anormais de toda espécie, de modo a evitar que "essa multidão de predispostos atinja o despenhadeiro ou seja tragada pela voragem da alienação mental" (ABHM, 1934, p. 64). Era preciso conter a "avalanche de degeneração" (ibid.), o que passava não apenas a incluir as medidas eugênicas propriamente ditas, mas sobretudo a modelagem psíquica dos indivíduos desde os primeiros instantes de vida. Para tanto, era necessário incluir como sujeitos psiquiatrizáveis diferentes matizes de irregularidades individuais do que poderiam vir a se tornar desvios adaptativos.

\section{$O$ interesse pelo psiquismo infantil}

Em um artigo de Hosannah de Oliveira (1933), aparece a noção de "psiquismo do lactente": fruto da ação reflexa e da afetividade, cuja plasticidade tornava justificável a intervenção médica o mais precocemente possível, de modo a garantir um desenvolvimento infantil saudável. Partindo da ação reflexa, encontramos uma descrição minuciosa das primeiras reações do recém-nascido ao meio externo, expressas por automatismos constitucionais, signos que seriam da existência arcaica do psiquismo. Aparentemente, estaríamos diante de um problema de ordem estritamente biológica. No entanto, com a afirmação da precocidade do psiquismo, sua plasticidade e a vulnerabilidade aos estímulos externos, ter-se-ia constituído um potente argumento para defender, pela busca pela normatividade neurológica, o interesse em intervir o mais precocemente possível na produção da anormalidade.

Mas a higiene mental não estava interessada em toda e qualquer criança, mas sim naquelas acometidas por debilidade mental, que deveriam ter não a assistência dos médicos, mas do Estado, que deveria amparar a família no cuidado a essas crianças. Em um artigo de 1939, Porto-Carrero (n. 1-2) explicita como debate de interesse nacional a criação de um espaço de "recolhimento" de crianças anormais e conclama o Estado a tomar para si esta causa. O que se considerava uma criança anormal? O modelo da lesão cerebral coordena a taxonomia: havia 


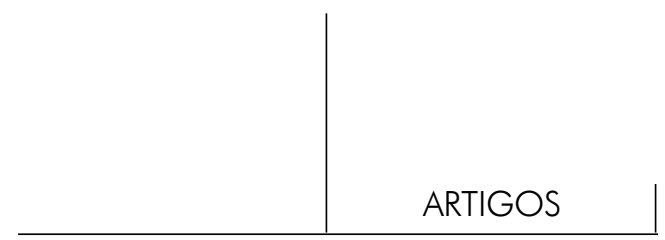

as crianças com lesões cerebrais graves, mas também as que tinham uma lesão leve que se manifestava como traços fronteiriços, como excesso de excitação. Seu interesse incidia justamente sobre o segundo grupo, passível de intervenção higienista. Às crianças alienadas, hospício; às perversas, malandras, desequilibradas, intervenção médica e tutela do Estado.

A família é condenada à incompetência no cuidado com os fillhos e parte desse comportamento anormal é tributada a ela, que não teria sabido educar adequadamente os filhos. Mas é a doença - heredosífilis, distúrbios hormonais, lesões nervosas - que comparece na etiologia que se traça para esses comportamentos. O Estado é convocado a prestar educação a essas crianças. À medicina caberia a prescrição de remédios, de educação moral e tratamento antisifilítico. Mas o que aí aparece como preocupação central é a reprodução dos anormais:

[...] as crianças anormaes crescem e vão constituir família, formando-se uma série de degenerados que vão povoar os hospícios ou praticar uma série de desatinos, atribuíveis á má educação e á perversidade e no entanto tudo dependente da herança neuro ou psicopatica que sobre eles pese. (Porto-Carrero, 1939, p. 4)

A infância passível de normalização ganha, portanto, importância renovada na LBHM. Nos programas dos ambulatórios de psiquiatria preventiva já existentes à época, a intervenção na infância era enfatizada. Dessa forma, regularmente os psiquiatras ofereciam serviços voltados para a prevenção de "acidentes nervosos da infância", por meio de aconselhamento às mães e amas, sob a responsabilidade de Gustavo de Rezende; assistência profilática aos "pequenos nervosos”, por Mauricio de Medeiros; tratamento e prevenção de reações antissociais na infância, por Heitor Carrilho; pesquisas genealógicas voltadas para orientação em higiene mental, por Floriano de Azevedo. Curiosamente, esse programa foi traçado após um breve período de crise da instituição, no ano de 1925, fomentado pelo interesse em conquistar adesão social ao projeto de "regeneração social" (Caldas, 1932, p. 72-73).

\section{O nascimento da euphrenia}

Um novo domínio discursivo no âmbito da higiene mental surgiria alguns anos mais tarde, em 1933: a "euphrenia". A designação, fruto de um neologismo cunhado por Mirandolino Caldas (1932a), visava situar estrategicamente o cuidado com a infância no meio caminho entre a eugenia e a higiene mental. Traduzida pelo próprio autor como "sciencia da boa cerebração" (Caldas, 1932, p. 30), a eufrenia consistia numa "eugenia psíquica". 


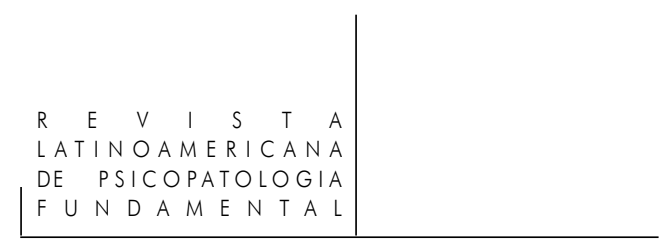

Inscrever a psiquiatria vintecentista apenas no âmbito da higiene não era suficiente para nomear seu projeto de intervenção social. A higiene, voltada para ensinar ao indivíduo e à sociedade a se precaver da doença, não designava bem o alcance do interesse regulatório da psiquiatria, senão na aplicação restritiva do conceito de higiene mental, voltado para a prevenção dos distúrbios psíquicos. Era necessário criar algo análogo ao "homem morfologicamente perfeito" da eugenia, o que no âmbito psiquiátrico seria traduzido por uma formação psíquica perfeita (Caldas, 1932, p. 30).

No entanto, o conceito de eugenia também parecia inadequado a esse interesse, pois, apesar de o valor eugênico dado à boa constituição ser útil à psiquiatria, filiação ético-política da qual ela se orgulhava, a "boa" formação do psiquismo não dependeria apenas da constituição transmitida hereditariamente, mas também do acompanhamento cuidadoso do desenvolvimento do psiquismo. Além disso, a hereditariedade psicológica possuía zonas de opacidade à leitura mendeliana, matriz de interpretação dominante entre eugenistas. Na tentativa de leitura da constituição da esfera psíquica, não era possível mais sustentar com segurança padrões de dominância e de recessividade, constatação que começava a gerar uma mobilização do saber psiquiátrico em outra direção.

Nesse sentido, cabia ao psiquiatra intervir na vida psíquica dos indivíduos desde a fase intrauterina, servindo de exemplo o artigo já referido de Oliveira (1933). Pelo neologismo "euphrenia", portanto, a psiquiatria pôde nomear a emergência de um novo domínio que precisava se distinguir da eugenia geral, pois nem seu objeto, nem suas táticas de regulação seriam as mesmas.

Nesse novo domínio, a eugenia continuava sendo a base a partir da qual a eufrenia poderia ser levada a cabo. Tanto é assim que, no plano de ação da eufrenia, em primeiro lugar, enuncia-se a "seleção nupcial", baseada na seleção de "bem dotados", capazes de produzir uma descendência mentalmente hígida; em seguida, cuidar-se-ia para que os de boa constituição genotípica tivessem boa capacidade de fecundação e que fosse possível ainda realizar uma seleção da natalidade de modo a evitar o nascimento de indivíduos disfrênicos, procedimentos qualificados como da ordem de uma "eufrenia genealógica".

Mas, como vimos, a eufrenia não se restringia à eugenia, e era necessário formular um conjunto de táticas condizente com essa expansão, que foi nomeado como "eufrenia médico-pedagógica", inspirada numa psicologia funcionalista, centrada na ideia de adaptação, que forneceria as bases para uma intervenção não mais psiquiátrica, mas neuropsiquiátrica. Essa era uma atualização que a deixava orgulhosa de seu futuro como disciplina centrada na função cerebral, e constituída pelo tão antigo e almejado substrato orgânico.

As ações diagnósticas e terapêuticas da Liga nesse momento se concentraram nas consultas psiquiátricas às crianças nervosas e na assistência 
social e às famílias dessas crianças. Testes psicológicos começam a ser aplicados como instrumentos de diagnóstico, uma vez que a análise da infância se fazia a partir de uma compreensão evolutiva, presente na ênfase que começava a ser dada ao desenvolvimento das crianças.

Aparece no texto de Coutinho (1939) um discurso que começa a salientar o desenvolvimento como um modelo de compreensão que faz surgir o critério da normalidade, sem que seja preciso recorrer, necessariamente, à ideia de degeneração. Seria a regularidade esperada para cada fase da vida que permitiria estabelecer os critérios prescritivos que especificam o que seria a anormalidade. Novo princípio de organização do discurso psiquiátrico que, a partir da década de 1940, vai paulatinamente substituir o discurso da degenerescência pelo da desestruturação. Freud é invocado no realce dado à infância na constituição da vida futura, mas a ideia em relevo são os prejuízos das dificuldades desta fase na adaptabilidade do indivíduo. É com essa chave que o autor discute o conceito do princípio de prazer e princípio de realidade, que põe em antagonismo o interesse individual hedonista, de um lado, e as exigências sociais, de outro.

A família seria esse ponto de acoplagem entre os interesses do indivíduo e as exigências sociais que, pela via da afetividade, produziria compensações para a renúncia a que estariam convocados, desde a infância, os indivíduos. Ela deveria ser o agente que pudesse difundir uma pedagogia de hábitos considerados saudáveis, aliada à criação de novos predicados morais pela ativação da afetividade infantil em relação a certas situações sociais, como em cerimônias cívicas ou religiosas, por exemplo. Mas isso não era incompatível com a subsistência do modelo da degenerescência, pois a ênfase pedagógica tinha também a intenção de interferir na atualização da carga constitucional que predispunha o indivíduo à anormalidade (Campos, 1934, p. 15). Num panfleto de divulgação do trabalho de eufrenia realizado pela Liga, intitulado "Exhortação ás mães", encontramos um discurso que tentava cooptar a família, especialmente a mãe, para ser um agente da vigilância eufrênica e aliada dos psiquiatras no seu projeto de normalização social, que se oferece como único saber legítimo para regular a convivência familiar e para salvar os futuros adultos do crime, da loucura e dos vícios:

Mãe extremosa!

Teus filhos são a relíquia mais preciosa que possues.

[...] Os menores distúrbios physiologicos te preocupam e te fazem soffrer e perder noites e mais noites...

O teu filho cresceu, tornou-se homem; a tua filha tambem tornou-se mulher.

Era o momento de sentires a felicidade integrada ao teu lar e a alegria de ter cumprido condignamente a tua missão de mãe.

[...] Não é raro, porém, apparecerem as terríveis decepções: teu filho que desde a infância se mostrara um menino teimoso e pugnaz, tornou-se um crimi-

Rev. Latinoam. Psicopat. Fund., São Paulo, v. 14, n. 4, p. 627-641, dezembro 2011 


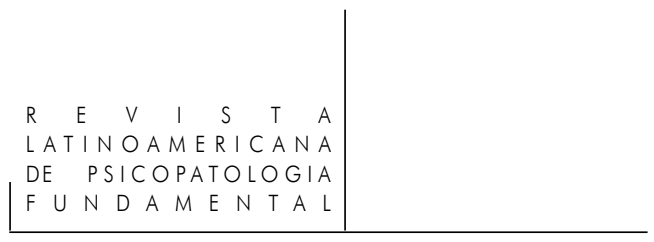

noso e se encontra agora na desolação do cárcere; tua filha, sempre cheia de esquisitices, foi internada num hospital psychiatrico.

Quanta tristeza! Quanta desilusão!

[...] Muitos desvios do psychismo são frutos da má orientação educacional. E são os Paes, não raro, os responsáveis por essas graves anomalias. E' que quasi todos, ainda os mais esclarecidos, são levados, insensível e involuntariamente, pelos sentimentos affectivos, que não lhes deixam ver os defeitos dos seus pimpolhos.

[...] É nas Clinicas de Euphrenia que poderás encontrar esses conselhos de que careces. [...] A finalidade principal desses serviços não é tratar os psychopatas e os degenerados: é, sobretudo, aperfeiçoar, cada vez mais, o delicado mechanismo de elaboração psychica (A clínica da euphrenia, 1932).

\section{A maquinaria erótica intrafamiliar a serviço da adaptação}

A função familiar de agente de ajustamento social das crianças não deveria mais, no entanto, ser realizada de forma aversiva. Esta é uma das razões que tornam o castigo condenável do ponto de vista da higiene mental. O castigo que representaria a hostilidade parental - frustra as expectativas de uma renúncia internalizada pelo indivíduo como algo da ordem do seu desejo, contrariando o regime adaptacionista que a higiene mental lutava por introduzir. Sem as compensações do amor parental, a criança resistiria, com mais frequência, aos apelos de ajustamento voluntário ao registro social, preconizado pela LBHM. Mas a ternura exagerada, por sua vez, era também recriminada: o excesso de proteção, de afetividade, de liberdade familiar seria igualmente nefasto para a adaptação do indivíduo às exigências sociais, que deveriam sempre prevalecer.

O que fica patente é que o projeto da higiene mental não poderia prescindir de uma regulação da economia afetiva intrafamiliar para obter êxito. O tema do "filho único" ilustra bem esse interesse. Num artigo de Murillo Campos (1934), a condição do filho único aparece como a causa de uma série de distúrbios neuróticos. Seu modelo de análise é a triangulação edípica, mas a leitura que ele realiza está ancorada na ideia de adaptação. Vejamos: a convivência exclusiva da criança com os pais ocasionaria um excesso de vigilância que, de um lado, favoreceria uma precocidade do desenvolvimento intelectual, tornando a criança um imitador do adulto. Essa aproximação demasiada comprometeria, por outro, a espontaneidade infantil e modificaria a relação da criança com o espaço da brincadeira, que seria do seu universo por excelência. Nesse sentido, muito do que era atribuído à herança, não passaria da reprodução de uma "educação defeituosa" (p. 4), fruto das psicopatias parentais. Isso poderia ser demonstrado 
pelo fato de que a convivência intensa e exclusiva com os pais exporia a criança às oscilações daqueles; ficaria também vulnerável à condição de dependência gerada pela concentração exagerada da atenção parental; "revelar-se-á um inapto para a vida"; diminuiria o interesse por contato.

$\mathrm{O}$ autor cita o desenvolvimento infantil e situa a interferência dos afetos parentais na formação da criança. Primeiro, o instinto de conservação seria preponderante e vinculado à nutrição, o que explicaria um interesse reflexo pela figura da mãe. Aos poucos, a criança perceberia a importância que tem para os pais, que são vistos como estando a serviço da vontade dela. Mas a frustração dessa percepção desencadearia um processo psicológico bem mais complexo: como o egoísmo seria constitucional (é essa a tradução que ele faz da noção freudiana de narcisismo) e a família detém, no primeiro momento, a exclusividade sobre o que se configura como universo infantil, os jogos ambivalentes começariam a aparecer. Afirma-se aí o desejo pelas figuras parentais, reproduzindo o conhecido itinerário edípico: desejo da mãe - introdução da figura paterna - castração. Os irmãos, no caso do filho único, estando ausentes, tornariam esse jogo afetivo muito mais intenso e dificultariam a renúncia "instintiva" exigida à adaptação social. O complexo de Édipo figuraria como causa dos sintomas neuróticos e psicóticos, atravessados pelo reflexo dessa intensa fustigação afetiva no interior da família, cuja aparição mais contundente seria a vida sexual desses sujeitos.

São indivíduos que, com frequência, revelam atrazos da sexualidade. Em muitos, a masturbação é a única forma por que chegam à satisfação erótica. Não são impotentes, mas apenas inhibidos sexuaes: - vêm na mulher, ora a tentação demoníaca, condemnavel, ora, simplesmente, a imago materna. A masturbação, nessas circunstâncias, equivale á castração ou desvirilização, por meio della supprimindo-se a tensão perturbadora, que causa horror. Em muitos, também persistem fortes traços de homossexualidade, quasi sempre de typo masochico. Não raros, fogem á genitalidade normal e procuram compensações de ordem intellectual ou neurótica. (Campos, 1934, p. 15)

A família nuclear havia chegado à saturação afetiva. O desafio era enfrentar os efeitos contingentes a essa aproximação intensa entre pais e filhos. O tema do incesto chegava à psiquiatria brasileira $\mathrm{e}$, com ele, alguns temores. Em primeiro lugar, que a família, que deveria zelar pela saúde mental de seus filhos, se convertesse ela mesma na fonte principal de agentes predisponentes à psicopatologia e à criminalidade. Além disso, estava em jogo, paradoxalmente, a ameaça ao interesse de que a psiquiatria, por sua atuação profilática, pudesse mediar a transformação da criança ajustada à condição de adulto normalizado e adaptado às exigências do meio, capaz de reproduzir esse modelo pedagógico na constituição de sua própria família.

Rev. Latinoam. Psicopat. Fund., São Paulo, v. 14, n. 4, p. 627-641, dezembro 2011 


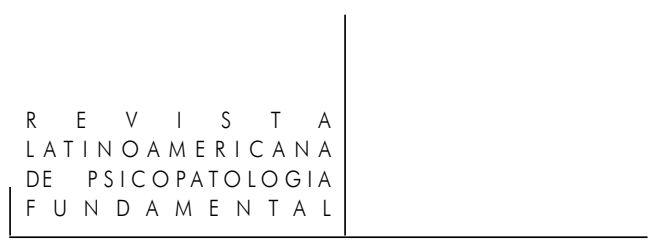

Ora, havia certos indivíduos que fracassariam no quesito da maioridade normalizada, justamente como efeito não desejado dessa saturação afetiva que, paradoxalmente, o saber médico havia ajudado a construir como norma familiar. A psiquiatria também visualizava que, como efeito do estado potencialmente incestuoso da família, fosse criada uma figura monstruosa: a de um adulto débil não mais do ponto de vista intelectual (desse ela já havia, como vimos, desistido), mas do ponto de vista emocional. Encoberto por esses temores estava justamente o interesse psiquiátrico pela persistência do infantil no adulto (Foucault, 2001), pois esse era o tema que passava a mobilizar seu saber e seu poder de intervenção não apenas na vida dos indivíduos, mas também na vida social.

\section{Considerações finais}

A solidariedade explícita entre a higiene mental, a educação sexual e a eugenia, campanhas paralelas que se processaram no Brasil entre as décadas de 1920 e 1940, deixava entrever o início de um processo de fragilização do discurso da degenerescência, que passa a conviver, já em meados da década de 1930, com o discurso desenvolvimentista, que centralizava na "adaptação" o objetivo a ser perseguido na busca de "regeneração social" do Brasil.

A higiene mental, campo que indexava claramente a produção de normalização psíquica ao registro sexual, entra em cena para tornar a criança um adulto normalizado, zeloso da família e da pátria, livre de toda e qualquer anomalia. O sexo das crianças é o ponto de entrecruzamento desses discursos, já que se tratava de uma instância que permitia dar visibilidade à economia erótica que constituía a relação entre pais e filhos.

Com efeito, aspirava-se interferir na antropologia vindoura: fabricar um indivíduo que, se não podia ser selecionado rigorosamente pela eugenia, deveria receber da medicina uma profilaxia mental (leia-se sexual) para ser hiperajustado à norma. Com efeito, o sonho de produzir normopatas em série, a partir da vigilância incessante do sexo das crianças e da economia emocional intrafamiliar, acalentou os novos saberes psi que surgiram a partir da higiene mental.

\section{Referências}

A Campanha pro-hygiene mental. Archivos Brasileiros de Hygiene Mental. Anno VII, no. 1, jan.-mar.1934.

Rev. Latinoam. Psicopat. Fund., São Paulo, v. 14, n. 4, p. 627-641, dezembro 2011 


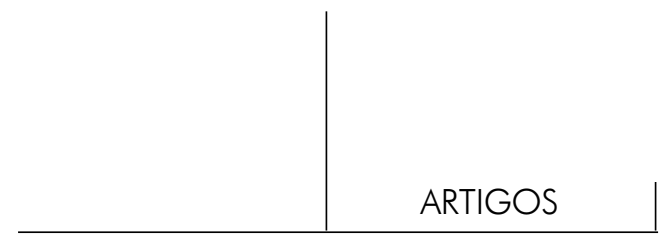

A CLínICA de euphrenia. Archivos Brasileiros de Hygiene Mental, Anno V, n. 2, mar. 1932.

Actas das reuniões da Liga Brasileira de Hygiene Mental. Sessão de 25 de fevereiro de 1928. Archivos Brasileiros de Hygiene Mental, v. 2, n. 1, 1929.

Caldas, M. A euphrenia: a sciencia da bôa cerebração. Archivos Brasileiros de Hygiene Mental, v. 5, n. 2, dez.1932a. mar. 1930.

. Hygiene mental no Brasil. Archivos Brasileiros de Hygiene Mental, v. 3, n. 3,

Campos, M. O filho único e a higiene mental. Archivos Brasileiros de Hygiene Mental, ano VII, n. 1, jan./mar. 1934.

Coutinho, M. A higiene mental nas diferentes idades. Archivos Brasileiros de Hygiene Mental, v. 12, n. 1-2, jan./ jun. 1939.

Fontenelle, J. P. Hygiene mental e educação. Archivos Brasileiros de Hygiene Mental, v. 1, n. 1, dez. 1925.

Foucault, M. (1967). A arqueologia do saber. 7. ed. Rio de Janeiro: Forense, 2005. . Em defesa da sociedade. São Paulo: Martins Fontes, 2005b. Curso do Collège de France do ano letivo 1975-1976. . A ordem do discurso. 6. ed. São Paulo: Loyola, 2000a. Aula inaugural no Collège de France em 1970.

. Os anormais. São Paulo: Martins Fontes, 2001. Curso do Collège de France do ano letivo 1974-1975.

Machado, R. et al. Danação da norma: medicina social e constituição da psiquiatria no Brasil. Rio de Janeiro: Graal, 1978.

Oliveira, H. de. Hygiene mental do lactente. Archivos Brasileiros de Hygiene Mental, v. 6, n. 3, jul./set. 1933.

Porto-Carrero, J.P. Ensaios de psychanalyse. Rio de Janeiro: Flores e Mano/Livraria Moura, 1929.

. Problemas de higiene mental. Arquivos Brasileiros de Higiene Mental, v. 12, n. 1-2, jan./jun. 1939.

Portocarrero, V. Arquivos da loucura: Juliano Moreira e a descontinuidade histórica em psiquiatria. Rio de Janeiro: Fiocruz, 2002.

REIS, J.R.F. "De pequenino é que se torce o pepino": a infância nos programas eugênicos da Liga Brasileira de Higiene Mental. História, Ciências, Saúde - Manguinhos, [on line], v. 7, n. 1, p. 135-157, 2000. Disponível em: http://www.scielo.br. Acesso em: 20 mar. 2009.

Rev. Latinoam. Psicopat. Fund., São Paulo, v. 14, n. 4, p. 627-641, dezembro 2011 


\section{Resumos}

(Eugenizing the soul: the constitution of "euphrenia" in the mental health project dedicated to youth, promoted by the Brazilian Mental Health League)

This article analyzes the establishment of "euphrenia" as a new domain for Brazilian psychiatry in its eugenic and hygienic approach to children's health. An analysis of medical and psychological knowledge regarding children's minds in Brazil in the 1920s and 1930s reveals the intense emotional climate in families as the basis for a project in social normalization, still focused on eugenics but also influenced by a psychology of adaptation.

Key words: Euphrenia, medical and psychological knowledge, family, Brazilian Mental Hygiene League

(Eugenizer l'âme: la constitution de "l'euphrenia" dans le projet d'hygiène mentale pour l'enfance de la Ligue Brésilienne d'Hygiène Mentale)

Cet article analyse la mise en place de "l'euphrenia" comme un nouveau domaine de la psychiatrie brésilienne dans son approche eugénique et hygiénique de l'enfance. L'analyse des connaissances médicales et psychologiques sur le psychisme de l'enfant au Brésil dans les années 1920 et 1930 révèle l'intense circulation affective intrafamiliale comme point de départ pour un projet de normalisation sociale, toujours centré sur l'eugénisme, mais maintenant imprégnée par une psychologie de l'adaptation.

Mots clés: Euphrenia, connaissances médicales et psychologiques, famille, Ligue Brésilienne d'Hygiène Mentale

(La eugenesia del alma: la constitución de la "euphrenia" en el proyecto de higiene mental direccionado a la infancia de la Liga Brasileña de Higiene Mental)

En este artículo se analiza la formación de la "euphrenia" como un nuevo dominio para la psiquiatría brasileña en su enfoque eugenésico e higiénico de la infancia. El análisis de los conocimientos médicos y psicológicos acerca de la psiquis infantil en Brasil durante los años de 1920 y 1930 revela la intensa circulación emocional intrafamiliar como punto de anclaje para un proyecto de normalización social, aún centrado en la eugenesia, pero ahora atravesado por una psicología de la adaptación.

Palabras claves: Euphrenia, conocimientos médicos y psicológicos, família, Liga Brasileña de Higiene Mental 
Citação/Citation: Oliverra, C. Eugenizar a alma: a constituição da "euphrenia" no projeto de higiene mental voltado à infância da Liga Brasileira de Hygiene Mental. Revista Latinoamericana de Psicopatologia Fundamental, São Paulo, v. 14, n. 4, p. 627-641, dez.2011.

Editor do artigo/Editor: Prof. Dr. Manoel Tosta Berlinck

Recebido/Received: 3.12.2010/ 12.3.2010 Aceito/Accepted: 18.2.2011/2.18.2011

Copyright: @ 2009 Associação Universitária de Pesquisa em Psicopatologia Fundamental/ University Association for Research in Fundamental Psychopathology. Este é um artigo de livre acesso, que permite uso irrestrito, distribuição e reprodução em qualquer meio, desde que o autor e a fonte sejam citados/This is an open-access article, which permits unrestricted use, distribution, and reproduction in any medium, provided the original author and source are credited.

Financiamento/Funding: Esta pesquisa é financiada pela CAPES - Coordenação de Aperfeiçoamento de Pessoal de Nível Superior e pelo Conselho Nacional de Desenvolvimento Científico e Tecnológico - CNPq/This research is funded by the CAPES - Coordenação de Aperfeiçoamento de Pessoal de Nível Superior and by the National Counsel of Technological and Scientific Development - CNPq

Conflito de interesses/Conflict of interest: A autora declara que não há conflito de interesses/The author declares that has no conflict of interest.

\section{Cristiane Oliveira}

Psicóloga, Mestre em Saúde Coletiva pelo Instituto de Saúde Coletiva da Universidade Federal da Bahia - ISC/UFBA (Salvador, BA, Br); Doutora em Saúde Coletiva na área de concentração Ciências Humanas e Saúde pelo Instituto de Medicina Social da Universidade do Estado do Rio de Janeiro - IMS/UERJ (Rio de Janeiro, RJ, Br), com estágio de doutorado no exterior (Université Paris VII, França); Docente do Instituto de Psicologia da Universidade Federal da Bahia - UFBA (Salvador, BA, Br); Docente da Escola Bahiana de Medicina e Saúde Pública (Salvador, BA, Br).

Av. Sete de Setembro, 1724/401 - Vitória

40080-004 Salvador, BA, Brasil

e-mail: cristianeolliveira@gmail.com

Rev. Latinoam. Psicopat. Fund., São Paulo, v. 14, n. 4, p. 627-641, dezembro 2011 